\title{
Modelling fluid flow and heat transfer tasks for testing PIR motion Sensor
}

\author{
Jakub Kazda ${ }^{1}$, Richard Matas ${ }^{1}$, and Jan Sedláček ${ }^{1}$ \\ ${ }^{1}$ New Technology - Research Centre (NTC), University of West Bohemia, Univerzitni 2732/8, \\ 30100 Plzen, Czech Republic
}

\begin{abstract}
The aim of this paper is to describe the methodology of modelling fluid flow and heat transfer tasks for testing electronic motion sensors, especially PIR (passive infra-red) motion sensors. The motion sensor measures changes in electromagnetic radiation in the infrared range caused by the movement of warmer objects compared to its surroundings. Distortion of the perception of the environment can lead to false alarms or insensitivity of the detector. PIR motion sensors should be designed and located to minimize heating of the lens by ambient air. The sensor may be exposed to conditions not specified in the basic standards. The practical part of this article deals with a non-standard test. A single-phase transient simulation in a specific test cabinet for two specific motion sensor models was performed using the computational fluid dynamics (CFD) method. The aim of these simulations was to evaluate the effect of hot flowing air on the lens and to compare the designs of both models. Comparison and analysis of the results showed that the test configuration does not guarantee a defined flow at the outlet of the pipeline, so a new configuration was designed.
\end{abstract}

\section{Introduction}

Nowadays, there are many ways to protect and secure property against fire or other damage (e.g. theft). One way is to use a PIR (passive infrared) motion sensor. A PIR sensor is a device working on the pyroelectric principle. The sensor measures different values of electromagnetic radiation in the infrared range, which enter through an optical lens to the pyroelement. Objects with a temperature higher than absolute zero $\left(-273.15^{\circ} \mathrm{C}\right)$ radiate their heat in the form of infrared radiation, which is invisible to the human eye but detectable to electromagnetic sensors. The size of the space monitored by the sensor is determined by its viewing angle. The pyroelement evaluates the change of infrared radiation, which leads to a change to the output voltage and, if necessary, an alarm is triggered $[1,2,3]$.

PIR sensors are tested according to EN 50131-X [4]. In normal operation, the sensor may be exposed to conditions other than those specified in the standard, such as placement near windows, various heat sources, fans, air conditioners, or above heating elements. This topic is not yet reflected in the available information sources.

This article deals with a non-standard test whose configuration was inspired by specific measurements in a laboratory. A single phase transient simulation in a test cabinet for two

\footnotetext{
* Corresponding author: mata@ntc.zcu.cz
} 
different models of motion sensors was carried out using computational fluid dynamics (CFD). The aim of these simulations was to evaluate the effect of hot flowing air on the lens and to compare the designs of the models. The second aim was the assessment of the quality of the test rig design in terms of stability of the velocity and temperature field. The project was therefore designed as a pilot to explore the potential of engineering simulations to identify the impact of off-design conditions on PIR sensors.

\section{Geometry and computational domain}

Two models of sensors marked Type 1 and Type 2 were chosen for simulations as shown in Figure 1. The computational domains around the sensors are determined by the dimensions of the test cabinet - see Figure 2. The arrangement of the cabinet does not directly comply with the EN standards; however, it provides stricter conditions for testing the sensors than the standards.
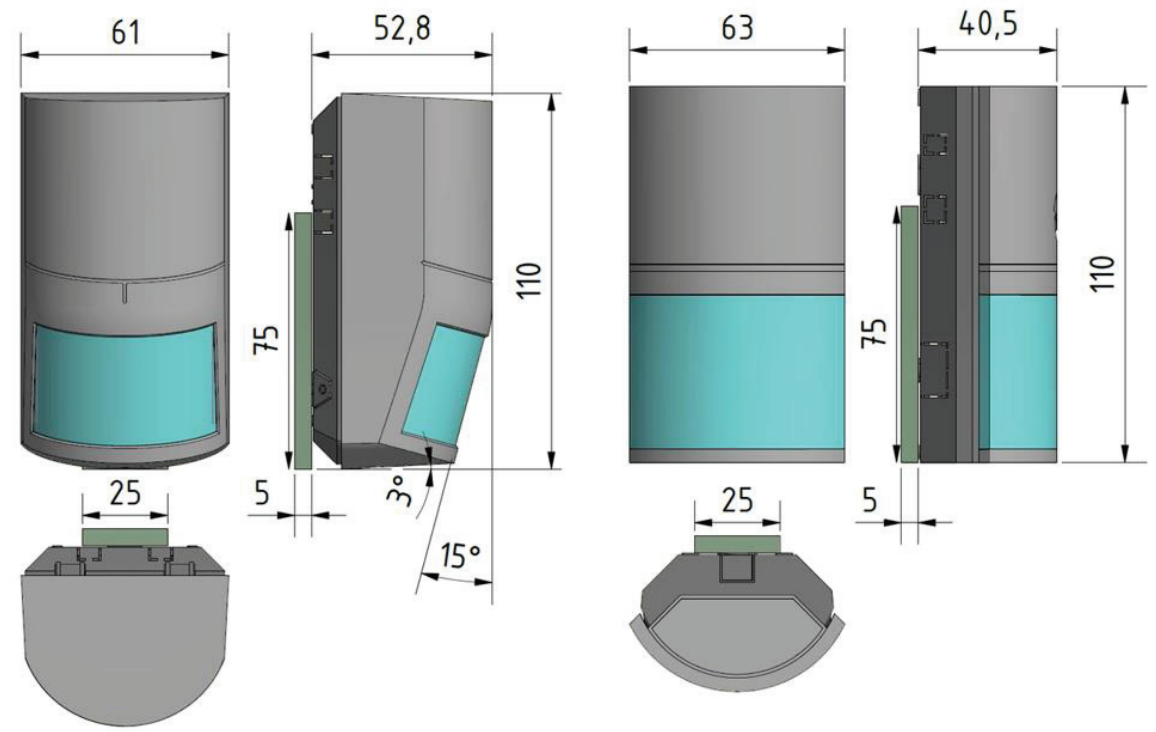

Fig. 1. PIR motion sensor models

The computational domain contains an air outlet into which the air flow enters through a $90^{\circ}$ pipe and a washer for mounting the sensors. The aim of this task is not to monitor the heat transfer through the walls of the cabinet, so only the inner surfaces of the cabinet were considered in the simulations. It is appropriate to include the volume of the PIR body in the transient simulation, due to heat accumulation, as the thermal properties of the volume are important for the surface temperature to monitor the warming of the body surface. Therefore the volume of the lens and the entire detector was also modelled to monitor the warming of the lens surface (Figure 2).

The output surfaces (ambient atmosphere) are marked in green and the input area in red - the orange colour indicates the location of the BOI body (body of influence) for setting up better local discretization. 

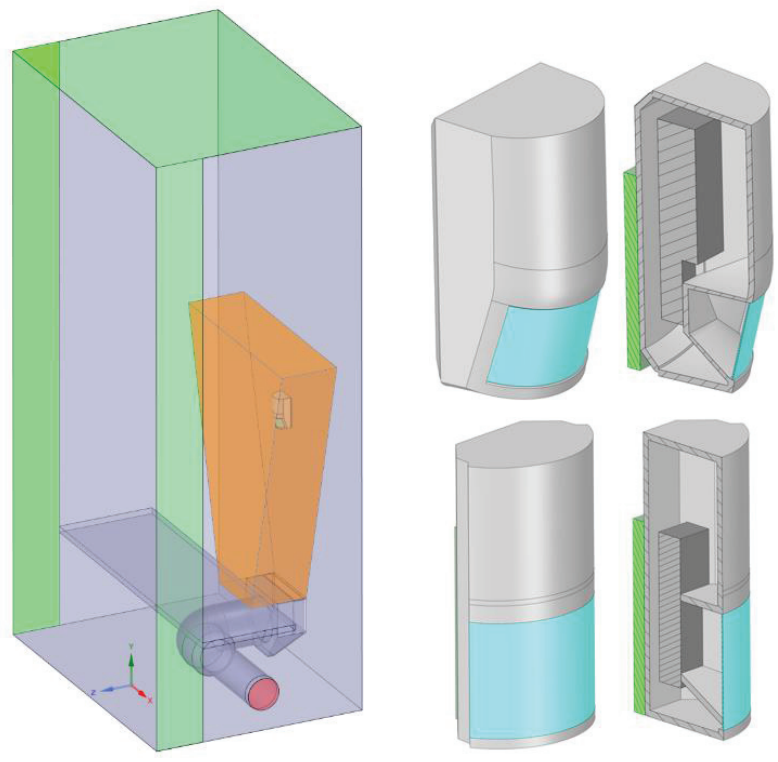

Fig. 2. Computational domain (left) and simplified models of sensor bodies (right)

\section{Solver setup and boundary conditions}

The CFD system ANSYS FLUENT 2020 R2 [5] was used for the simulations. The SST $\mathrm{k}-\omega[6,7]$ was chosen as a turbulent model, the energy equation was included as well. For the mesh independence study, a stationary type of calculation with averaging of values was chosen. A transient solver was chosen for the final simulations, because it is important to capture the vortices and fluctuations around the sensors.

The gravitational acceleration was set to $9.81 \mathrm{~ms}^{-2}$. The material properties of all the elements were set according to the manufacturer's data. The flowing air was set as an incompressible ideal gas - the density depends only on the temperature.

A turbulence intensity of $2 \%$ and a (Kolmogorov) turbulence scale of $4.8 \cdot 10^{-4} \mathrm{~m}$ were set. The inlet air temperature was set at $35^{\circ} \mathrm{C}$ with a flow velocity of $0.7 \mathrm{~ms}^{-1}$. The temperature was set to $20^{\circ} \mathrm{C}$ and the pressure to $101.325 \mathrm{kPa}$ at the outlet. A no-slip condition was set on the walls and the heat transfer coefficient was set to $10 \mathrm{~W} /\left(\mathrm{m}^{2} \mathrm{~K}\right)$.

\section{Computational mesh}

The detector interior, solid bodies and whole test cabinet domain were meshed with conform polyhedral meshes, because these sections are geometrically suitable for these types of elements. The polyhedral elements are able to surround complex geometric shapes and have a high number of adjacent cells, so it achieves a generally higher accuracy and stability then tetrahedral elements.

In order to ensure the accuracy of the CFD results from the simulation, a mesh independence study was made. Nine mesh versions of the Type 1 model were created for this study. All the meshes satisfy the recommended quality limits for polyhedral meshes. The 
mean values and RMSE fluctuations of velocity magnitude and total temperature were monitored (in stationary simulations) at specified surfaces, see Figure 3.

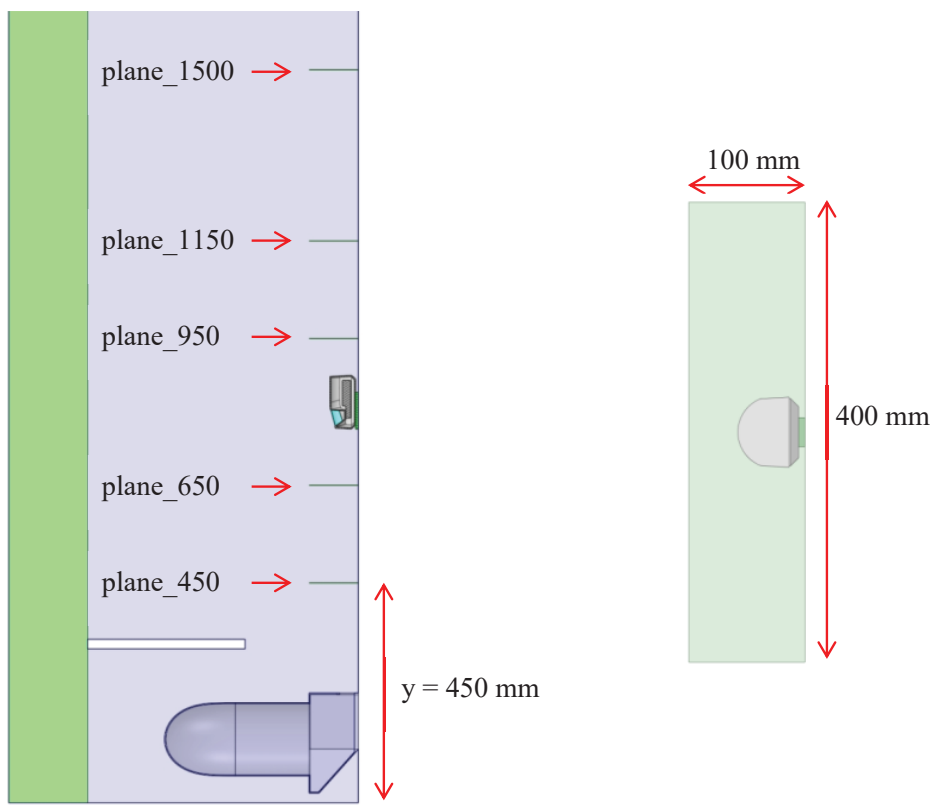

Fig. 3. Surfaces for evaluating the mesh independence study

The results of the mesh independence study are shown in Figures 4 and 5. It can be seen that the values obtained are quite strongly mesh dependent for the first five versions of the mesh and only weakly dependent for the next four versions. For the purpose of this work, the sixth version of the computational mesh with about 8.7 million polyhedral cells was chosen as the applicable discretization level.

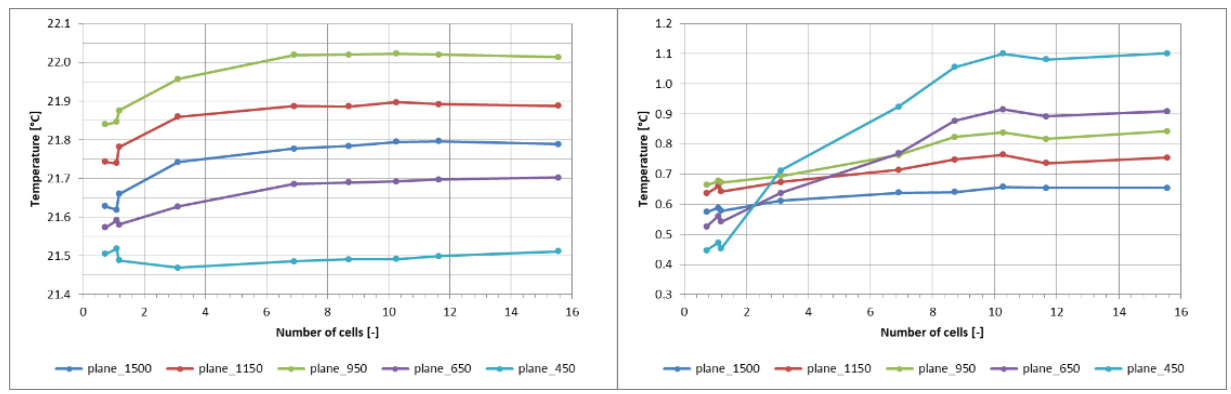

Fig. 4. Mean temperature (left) and RMSE temperature (right) 

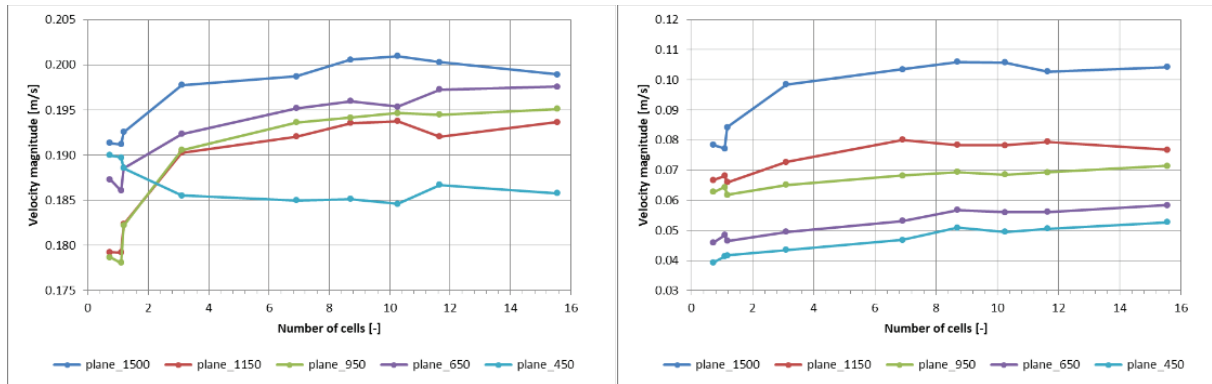

Fig. 5. Mean velocity magnitude (left) and RMSE velocity magnitude (right)

Below in Figure 6 is a preview of the selected mesh. After evaluating the optimal mesh, the same mesh generation setting was also implemented on Type 2.
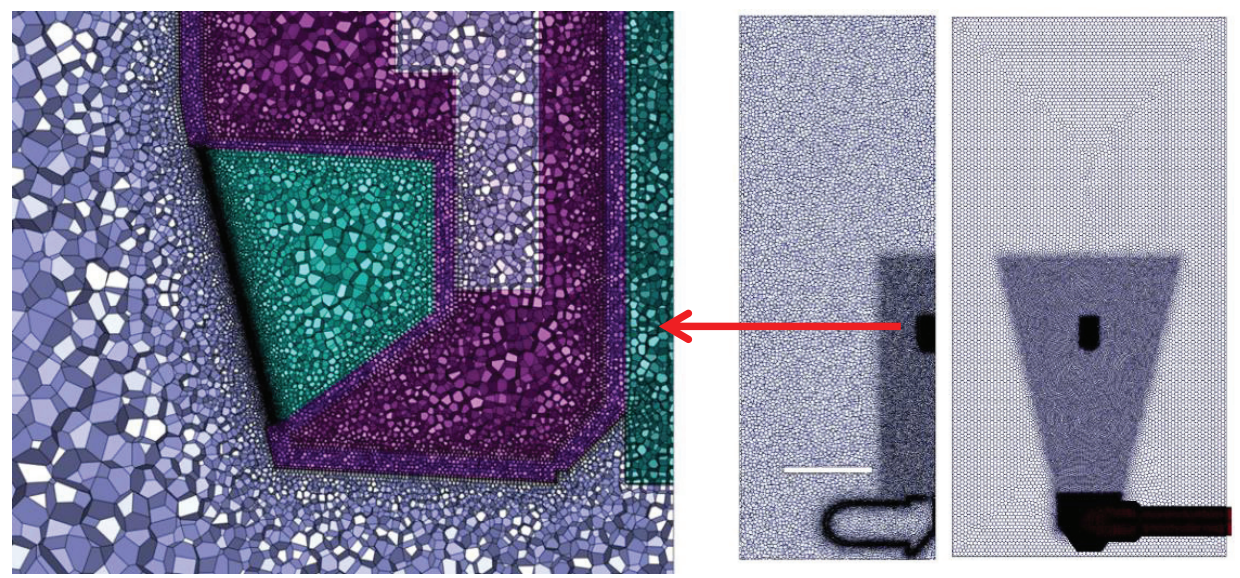

Fig. 6. Computational mesh - detail and general views

\section{Methodology of evaluating the results}

Figure 7 shows the planes and points and their locations where important quantities were monitored. The layout is the same for both sensor models. The xy plane is at a distance of $685 \mathrm{~mm}$ from the front (in the middle of the pipe opening). The planes for the mesh study are also used for evaluation.

A steady-state simulation was used for the first run together with an additional 30 time steps of non-steady-state simulation. The evaluation was carried out during an additional 300 time steps of $5 \cdot 10^{-4} \mathrm{~s}$.

All the results were evaluated relatively, thus the values are normalized by the maximum value from the stationary simulation of Type 1 . 

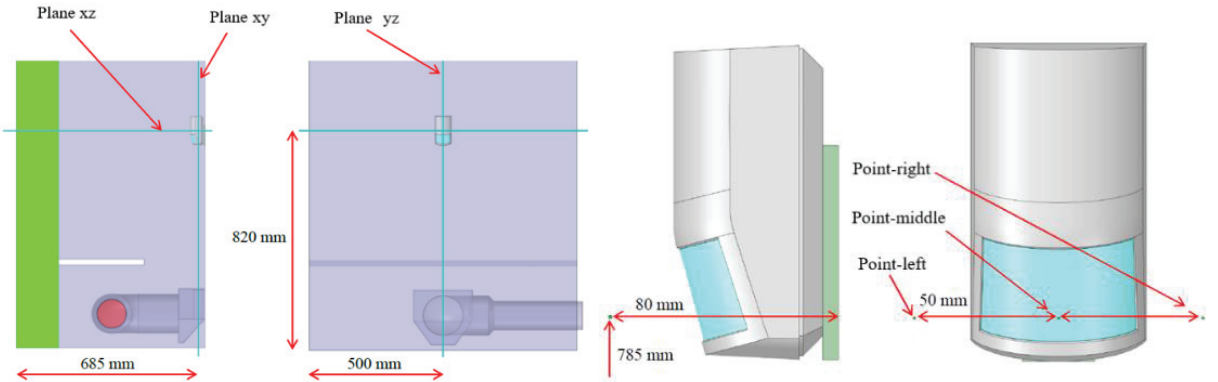

Fig. 7. Methodology of evaluation

\section{Results of the CFD simulations}

The normalized temperature contours in Figure 8 show a slightly non-stationary stream of warmer air. This heat propagation caused by flow along the wall also indicates the importance of proper placement of the detector in the space, as heating of the lens can adversely affect the function of the sensors. By comparing the generated contour time sequences over time, the pulsating nature of the outgoing warm air stream was observed

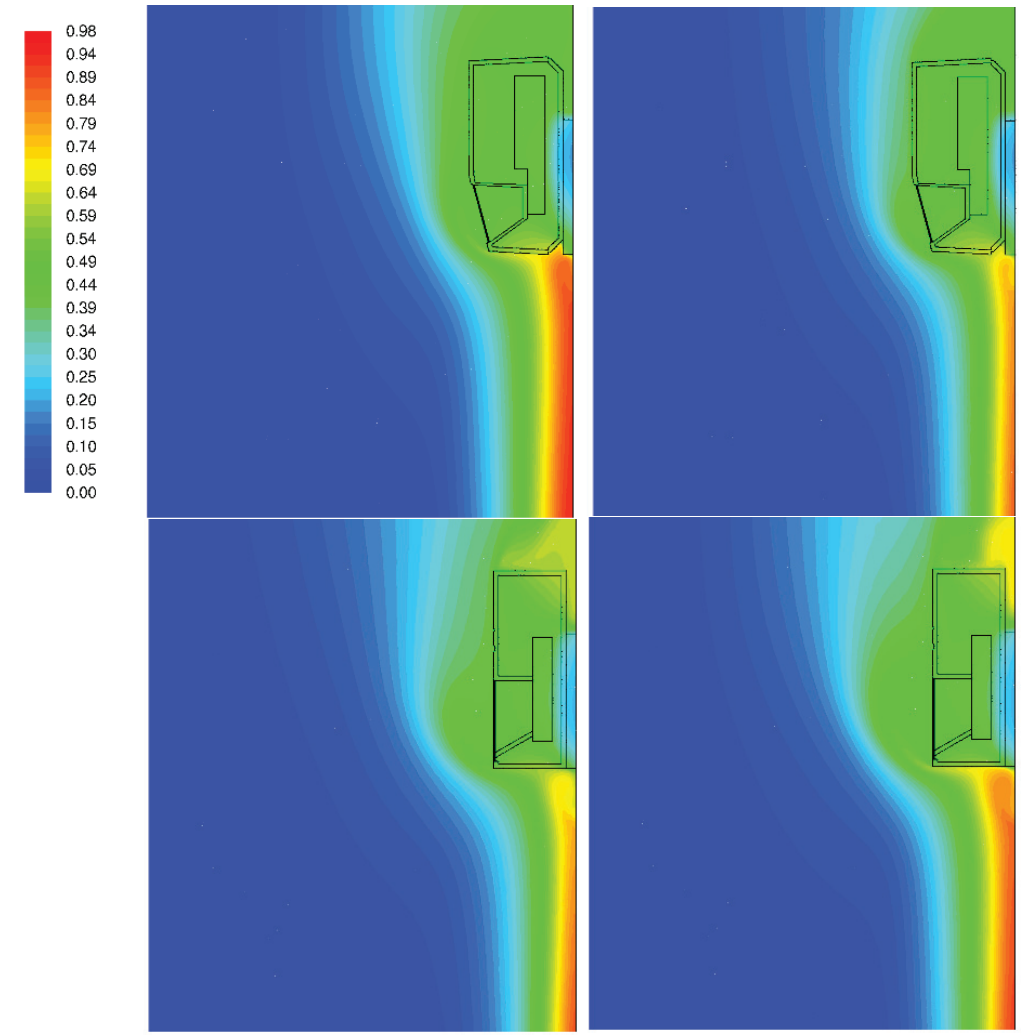

Fig. 8. Contours of the normalized temperature at $7 \mathrm{~s}$ and $12 \mathrm{~s}$, plane yz - Type 1 (up) and Type 2 (down) 
It was expected (and confirmed by calculations) that after the impact of the flowing medium on the lower edge of the detector, the flow splits. This situation is shown in Figure 9 and it also shows the inhomogeneous flow in the test cabinet.
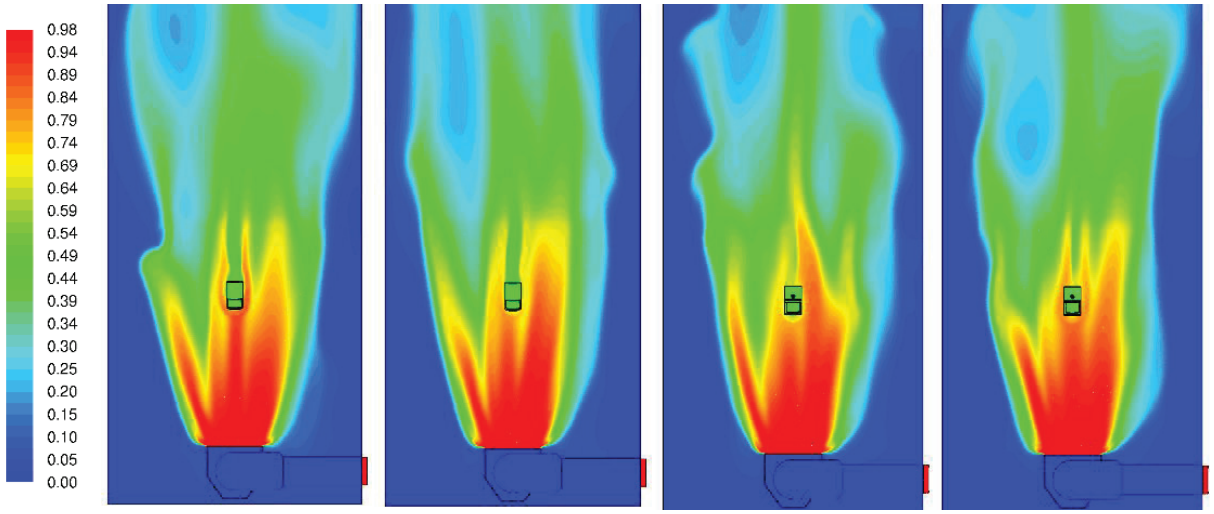

Fig. 9. Contours of the normalized temperature at $7 \mathrm{~s}$ and $12 \mathrm{~s}$, rear wall - Type 1 (left) and Type 2 (right)

Figure 10 shows the flow field around the sensor and the separation of the flow in front of the lens. The flow separation is more extensive for the Type 2 model. This effect is caused by the geometry of Type 2 which is more sensitive to the flow separation than Type 1 .

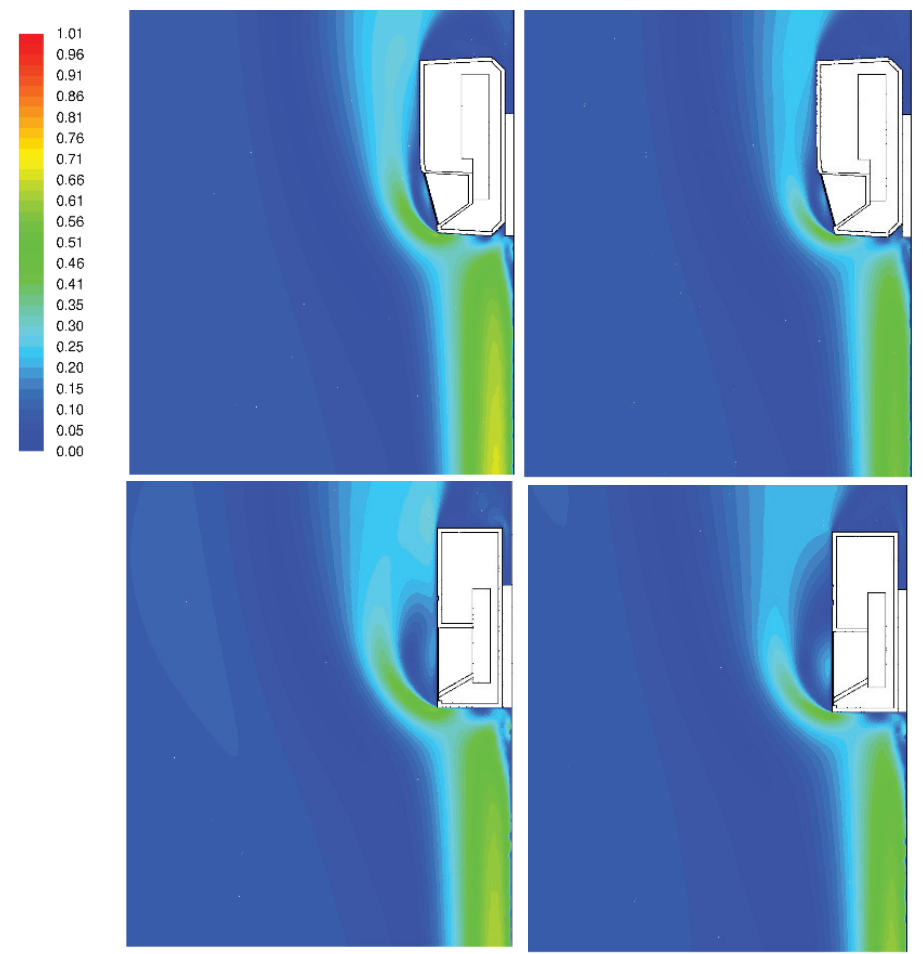

Fig. 10. Contours of the normalized velocity mag. at $7 \mathrm{~s}$ and $12 \mathrm{~s}$, plane yz - Type 1 (up) and Type 2 (down) 
The results in Figure 11 show that the flow for Type 2 is more unstable than Type 1. The results also show, similar to the results in Figure 9 for temperatures, that the flow from the inlet pipe is not symmetrical or stable.

This shows that the design of the test cabinet and especially the air outflow from the supply pipe is not satisfactory. The geometry of the circular duct (especially the elbows and the outlet) does not allow a homogeneous flow of the warm air in the cabinet; the flow is unstable and undefined.

The shape of the Type 2 sensor also causes higher fluctuation compared to Type 1, but the differences are not large. This finding is supported by the monitoring of temperatures and velocities during the unsteady simulation - see the normalized values from various points in the computational domain of both types in Figure 12. More detailed information about the modelling and the results can be found in the work [8].

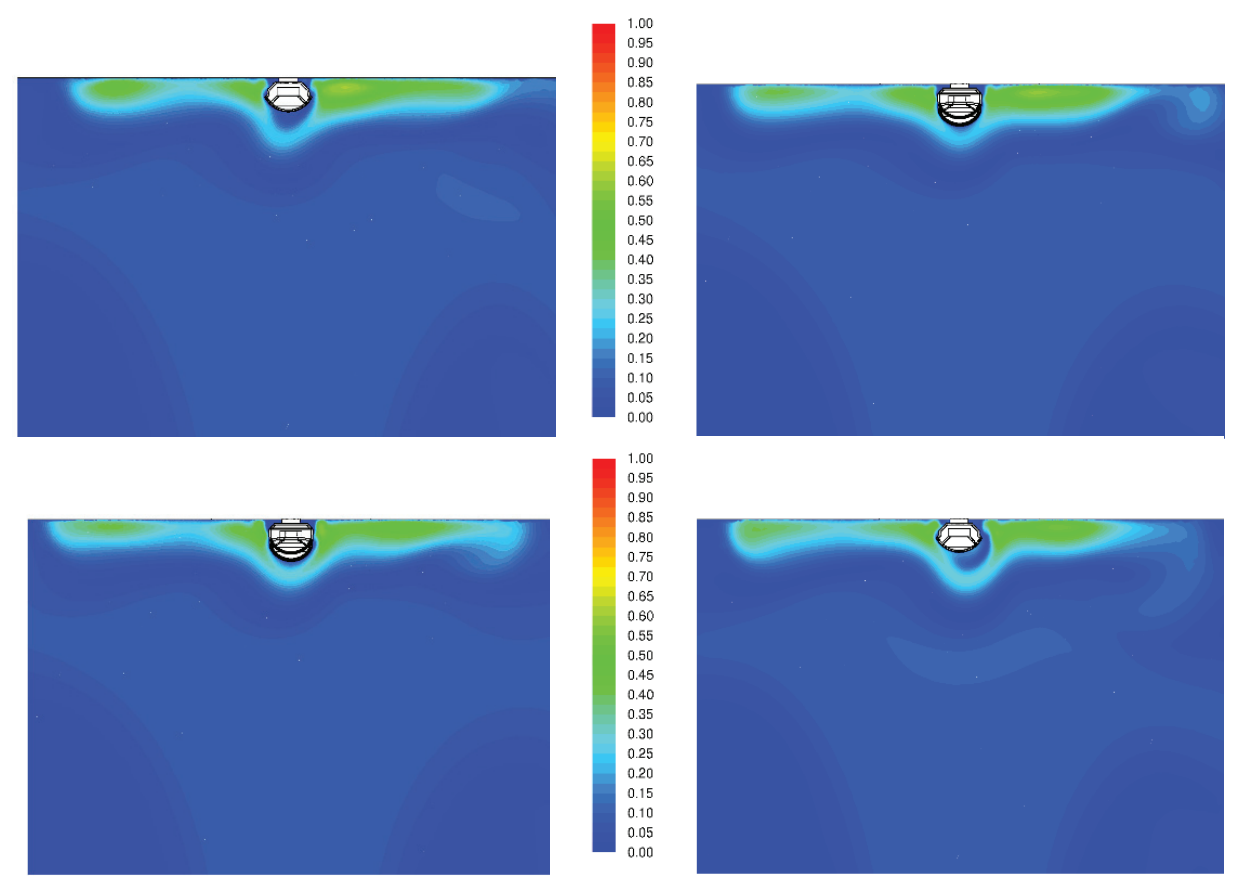

Fig. 11. Contours of the normalized velocity mag. at $7 \mathrm{~s}$ and $12 \mathrm{~s}$, plane xz, Type 1 (top) and Type 2 (bottom) 

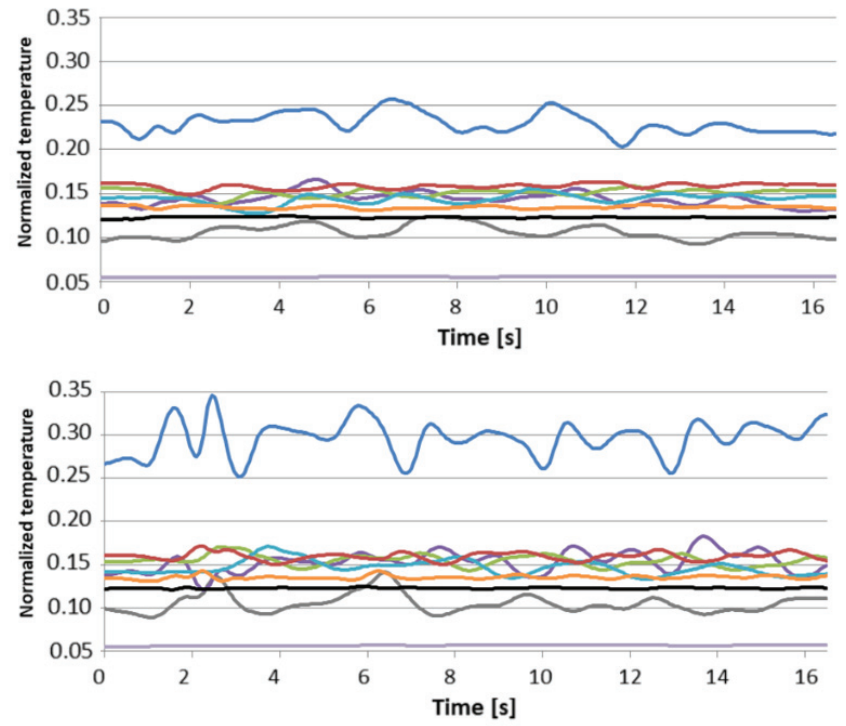

Fig. 12. Temperatures monitored during unsteady simulation - Type 1(up) and Type 2 (down)

\section{New design of the test cabinet}

Based on the findings described above, a new test cabinet for non-standard PIR testing was designed. It has a more suitable design of the inlet pipe, which guarantees a homogeneous flow at the outlet of the pipe. A fan is located behind the inlet, followed by a heater, an elbow with internal inserts and a flow conditioner. To change the flow pattern, a properly designed element can be placed at the outlet of the supply pipe. The PIR sensors can be mounted in various ways. A preview of the new configuration can be seen in Figure 13.
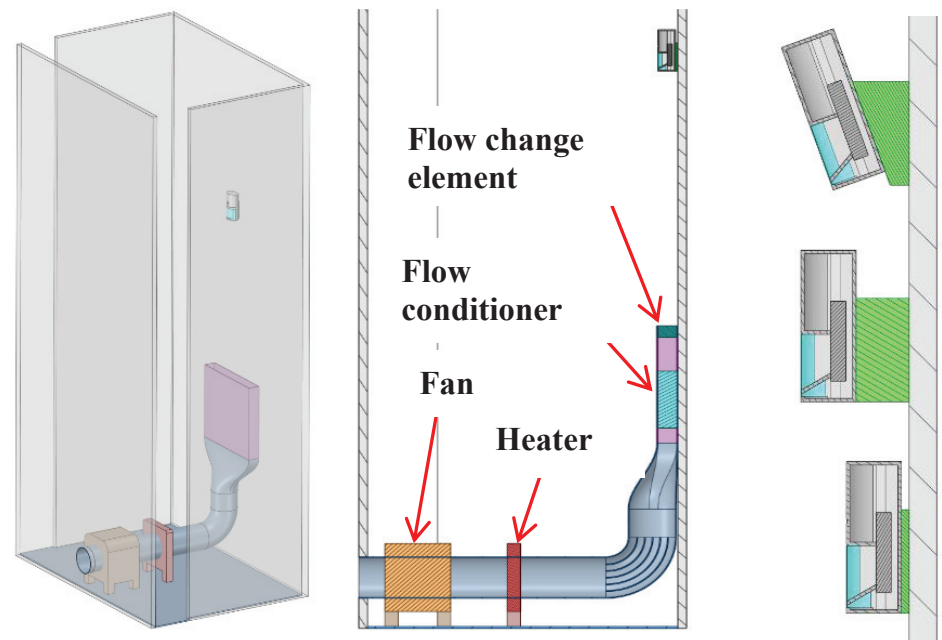

Fig. 13. The new test cabinet for PIR sensors for testing in off-design thermal conditions 


\section{Conclusions}

PIR motion sensors should be constructed and, above all, positioned so that the lens is warmed as little as possible by the ambient air. Different mounting conditions of PIR sensors that may occur in practice are as yet not well researched. The knowledge gained can help manufacturers and users to address the placement of sensors outside the standard conditions. Basic engineering principles regarding the enveloping of PIR sensors by warm flowing air were tested using numerical simulations. The results of the simulations can help in selecting a suitable location for measuring velocity or temperature in experimental measurements. They also show the importance of the shape of the sensor with respect to the interaction with the flowing warmed air. Finally, the test cabinet used for non-standard testing of sensors was analysed and based on the results, a new design was proposed for testing sensors in nonstandard conditions, eliminating the shortcomings of the original design.

The results were developed within specific research (UWB SGS-2019-021) and contract research.

\section{References}

1. G. Cirino, L. G. Neto, "Design of cubic-phase distribution lenses for passive infrared motion sensors", Sao Paulo: The International Society for Optical Engineering, 2013. $10.1117 / 12.487786$.

2. M. Bori, "Možnosti ověření vlastností PIR detektorư", Zlín: Bakalářská práce, Univerzita Tomáše Bati ve Zlíně, 2010 (in Czech).

3. L. Michalec, "PIR detektor: skvělý sluha, ale zlý pán", Vyvoj.hw.cz. [Online] 19. 3 2013. [Citation: 3. 12. 2020] https://vyvoj.hw.cz/automatizace/pir-cidlo-skvely-sluhaale-zly-pan.html (in Czech).

4. EN 50131-X, Alarm systems - Intrusion and hold-up systems.

5. ANSYS Fluent User's Guide 2020 R2, ANSYS, Inc., 2020.

6. F. R. Menter, "Zonal Two Equation k- $\omega$ Turbulence Models for Aerodynamic Flows", AIAA Paper 93-2906.

7. F. R. Menter, "Zonal Two Equation k- $\omega$ Turbulence Models for Aerodynamic Flows", AIAA Paper 93-2906.

8. J. Kazda, "Modelování úloh s prouděním a sdílením tepla určených pro testování elektronických čidel”, Plzeň: Diplomová práce, Západočeská univerzita v Plzni, 2021 (in Czech). 